\title{
New Additive Type Amorphous-Carbon/Zn Modifier of the Thermal Conductivity of Alcohol Fuel
}

\author{
Bruno Santos Potensa ${ }^{a}$, Grazieli Olinda Martins ${ }^{\text {b }}$, Silvania Lanfredi ${ }^{c}$, \\ Marcos Augusto Lima Nobre ${ }^{d}$ \\ Laboratório de Compósitos e Cerâmicas Funcionais- LaCCeF, Fac de Ciências e Tecnologia - \\ FCT, Univ Est. Paulista - UNESP, P.O Box 467, CEP 19060-900, Presidente Prudente-SP, \\ Brazil. \\ ab.potenza@yahoo.com, ’ grazi.martins2@gmail.com, c silvania@fct.unesp.br,
}

Keywords: nanocomposite, thermal conductivity, biofuel, additive, Carbon/Zn .

\begin{abstract}
A functional inorganic-additive modifier of the thermal conductivity of biofuel type alcohol anhydrous was developed based on an amorphous carbon nanocomposite containing dispersed zinc. Dispersion and modification of thermal conductivity in biofuels type anydrous alcohol were considered, as well as in petro-diesel and a blend of biodiesel and petro-diesel. Fuels, alcohol, diesel and biodiesel acted as a continuous medium dispersing the particles of $\mathrm{C} / \mathrm{Zn}$. Both thermal conductivity and thermal resistivity measurements were carried out showing that the amorphous nanocomposite particles $\mathrm{C} / \mathrm{Zn}$ act as an additive to improve the thermal conductivity of alcohol. The same phenomenon has not been identified for diesel, biodiesel and its blends. Increasing the thermal conductivity of the alcohol generated by adding of particles is discussed as a function of the concentration and molecular interactions on the surface of additive particles.
\end{abstract}

\section{Introduction}

In recent years have been much discussed the replacement of non-renewable fuels by biofuels. Biofuels are not derived from non-renewable source and cause less environmental impact. The biodiesel is a biofuel, product of the process of esterification or transesterification of oils and fats, and chemically composed by mono-esters of fatty acids. Biodiesel is an alternative fuel sources to replace the diesel for environmental reasons. Fuel alcohol or also called ethanol is a biofuel obtained by anaerobic fermentation processes, their main source of raw materials are sugars (glucose, starch, cellulose etc. ...), with chemical formula $\mathrm{CH}_{3} \mathrm{CH}_{2} \mathrm{OH}$ [1]. Diesel oil is obtained from a non-renewable source, the oil, basically composed of hydrocarbons. Solid additives have been considered as lubricants. In this work was developed a new nanocomposite based on amorphous carbon with zinc metal disperse. Functional composite materials exhibit properties superior to the individual components. The material was prepared according to the polymer precursors method [2]. Properties, such as modifying additives of the thermal conductivity of fuels and its molecular interaction with the nanoparticle were investigated. The effect of the concentration of nanoparticles in fuels and their influence on the thermal conductivity is discussed.

\section{Materials and Methods}

Using a glass pycnometer with thermometer were determined the densities of the fuels, alcohol, diesel and biodiesel. In an analytical balance was measured the mass of the pycnometer. The pycnometer was removed from the balance and filled with fuel, taking care to not form air bubbles. Next, the mass of the fuel was measured. The volume of the pycnometer was recorded, with its full capacity. From these values, mass and volume of liquids, it was possible to determine their respective densities, as shown in equation (1).

The density $(\rho)$ of a liquid is the ratio between its mass $(\mathrm{m})$ and volume $(\mathrm{V})$ [3]: 


$$
\rho=\frac{m}{V}
$$

Through the density values of fuels (alcohol, diesel and biodiesel) was possible the preparation of nanocomposite dispersions of amorphous carbon / $\mathrm{Zn}$. The functional nanocomposite amorphous carbon / Zn was prepared following the Pechini method, with carbon/metal ratio of 3:1. The method of synthesis is described below [2].

In a beaker with heating and stirring, salts of zinc nitrate hexahydrate in monoethylene glycol was added. After this, was added citric acid, initiating the polyesterification reaction. The starting reaction is marked by the release of water vapor and $\mathrm{N}_{2} \mathrm{O}_{4}$. The extinguishing of the gas release of nitrogen tetroxide, with staining orange-brown, marks the end of the esterification reaction, yielding a high viscosity polymer gel at around $120^{\circ} \mathrm{C}[4,5]$. The material was allowed to cool for 24 hours, and then subjected to a primary calcination at around $300{ }^{\circ} \mathrm{C}$ in an inert atmosphere of air. Then, an expanded resin or also called "puff" was obtained. This material was deagglomerated and passed through a sieve with a 325 mesh particle size, receiving the name of functional nanocomposite amorphous carbon type / Zn or C / Zn. Fuels, alcohol, diesel, biodiesel and blends of diesel /biodiesel acted as a solvent, dispersing the C/Zn nanoparticles. Dispersions of 60, 120 and 240 ppm of amorphous carbon / zinc were prepared. The mass of the C / $\mathrm{Zn}$ were weighed for the $80 \mathrm{ml}$ of dispersion. The dispersions were prepared in a beaker of $100 \mathrm{ml}$. Ultrasound bath for dispersion and homogenization of nanoparticles to the solvent was used [6]. The effects of the addition of nanoparticles in fuels on the thermal conductivity and thermal resistivity was analyzed by the KD2 PRO DECAGON analyzer, with accuracy of $\pm 0,01 \mathrm{~W} / \mathrm{mK}$. This technique follows the Application of Council Direction 89/336 / EEC [7], which follows the international standards EN55022: 1987 and EN500082-1: 1991 [8]. For calculations of the thermal conductivity and thermal resistivity were used equations (2) and (3), respectively.

$$
K=\frac{q}{4 \pi m}
$$

where $\mathrm{k}(\mathrm{W} / \mathrm{mK})$ is the thermal conductivity, $\mathrm{q}(\mathrm{W})$ is the amount of heat produced per unit time and $\mathrm{m}$ is the slope coefficient of the straight line. The thermal resistivity was determined by the following equation:

$$
\rho^{\prime}=\frac{1}{K}
$$

where $\rho$ ' $\left({ }^{\circ} \mathrm{C} . \mathrm{cm} / \mathrm{W}\right)$ is the thermal resistivity, which is defined by the inverse of thermal conductivity. Thermal conductivity and thermal resistivity measurements were also performed for the each one of fuels to comparative purposes.

\section{Results and Discussion}

The material synthesized by the polymeric precursor method was characterized by the X-ray diffraction technique, receiving the name of functional nanocomposite of the amorphous carbon type with metallic zinc dispersed, or C/Zn. Fig. 1 shows the XRD pattern of the C/Zn material calcined at $300{ }^{\circ} \mathrm{C}$ for 2 hours, in static air atmosphere. The sample showed a diffraction pattern characteristic of amorphous structures for the carbon matrix. The few peaks related to the metallic zinc is due to small amount of material present in the sample. 


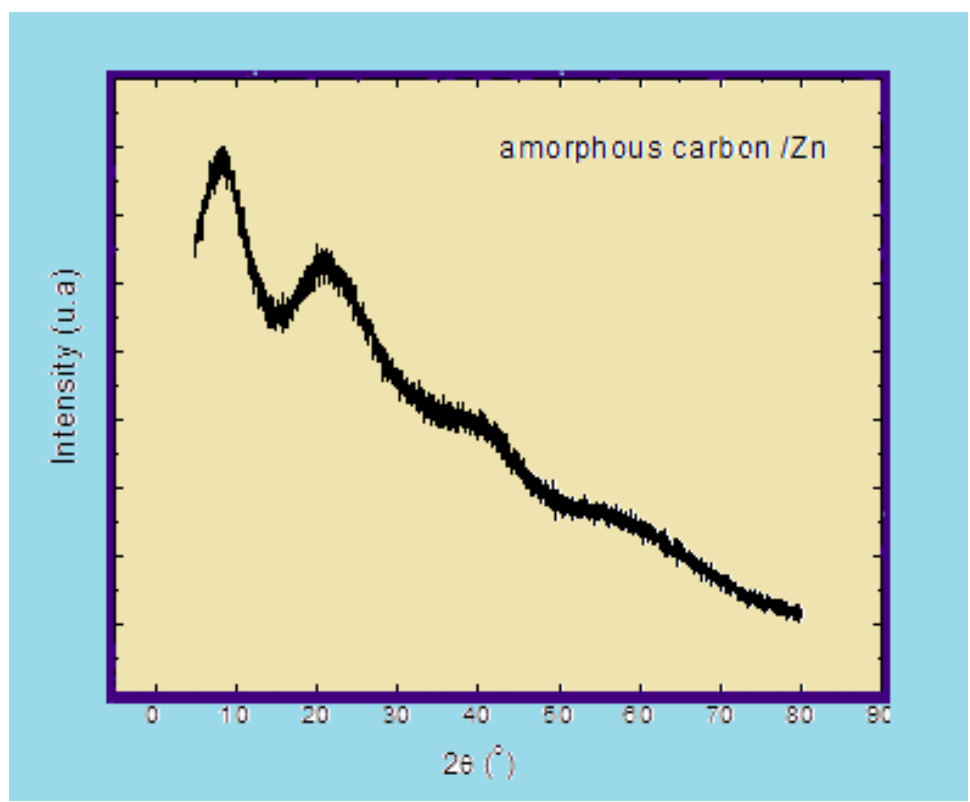

Fig. 1: XRD diffraction patterns of the $\mathrm{C} / \mathrm{Zn}$.

Fig. 2 shows the FT-IR transmittance spectrum of the of the C/Zn.

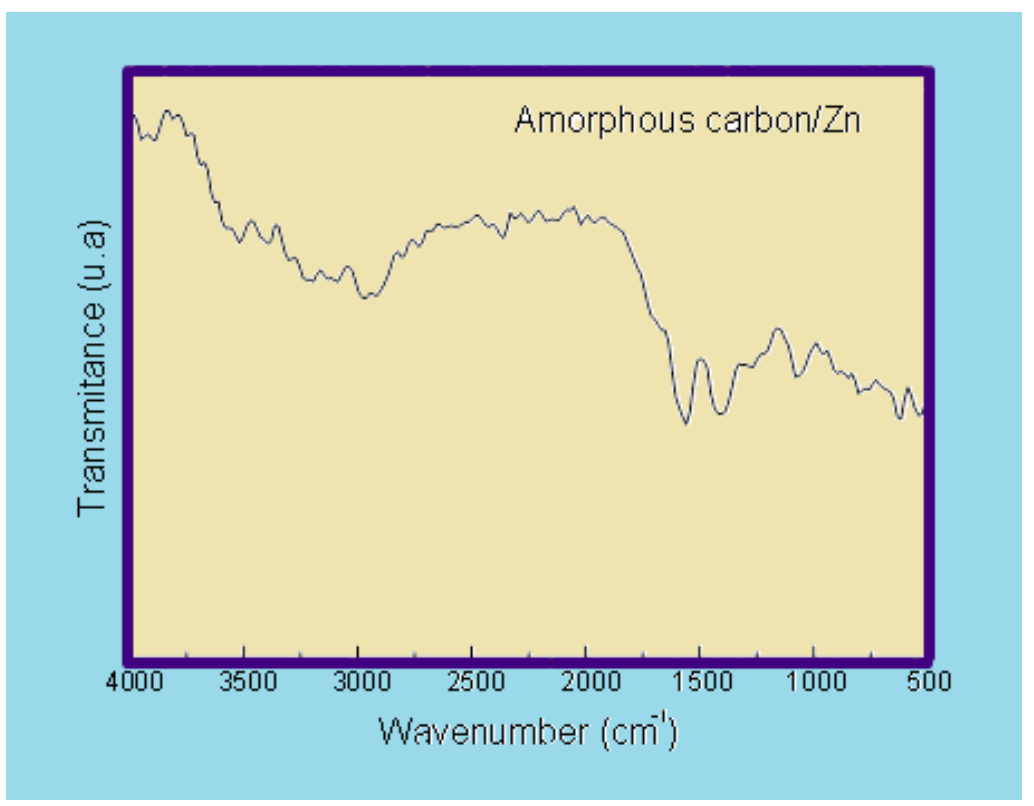

Fig. 2: FT-IR transmittance spectrum of the $\mathrm{C} / \mathrm{Zn}$.

According to Fig. 2, the small amount of metallic zinc dispersed in the carbon matrix was not sufficient to show bands in the infrared spectrum. Stretching and bending vibrations of the $\mathrm{OH}$ groups in the matrix of amorphous carbon was observed. Stretching bands, assigned to $\mathrm{CO}$ and $\mathrm{C}=\mathrm{O}$ bonds, were observed between 1300 and $1500 \mathrm{~cm}^{-1}$. The carbonyl group can be identified at $1658 \mathrm{~cm}^{-1}$. The broad band characteristic of CO corresponds to the largest amount of amorphous carbon present in the nanocomposite with ratio carbon / metal equal to 3: 1 [9].

Table 1 lists the density values, thermal conductivity and resistivity of pure fuels. 
Table 1: Density measurements, thermal conductivity and thermal resistivity of fuels.

\begin{tabular}{cccc}
\hline Fuel & Density $(\mathbf{g} / \mathbf{m l})$ & $\begin{array}{c}\text { Thermal } \\
\text { Conductivity }(\mathbf{W} / \mathbf{m K})\end{array}$ & $\begin{array}{c}\text { Thermal Resistivity } \\
\left({ }^{\circ} \mathbf{C . c m} / \mathbf{W}\right)\end{array}$ \\
\hline $\begin{array}{c}\text { Ethyl Alcohol } \\
\text { Anhydrous } \\
\text { Diesel }\end{array}$ & 0.82342 & 0.187 & 535.5 \\
Biodiesel & 0.88819 & 0.127 & 788.2 \\
$\begin{array}{c}\text { Mixture of Diesel } \\
\text { and Biodiesel }\end{array}$ & 0.92484 & 0.156 & 640.9 \\
\hline
\end{tabular}

The density of the diesel and biodiesel blend was determined by the weighted average. The ratio of each component is $50 / 50$ for $80 \mathrm{ml}$ of solution. For dispersion and homogenization of nanoparticles in the solvent was used ultrasound bath. In ultrasonic dispersion the compression and decompression waves cause molecular collisions of high intensity generating large degree of agitation, due in part to the large thermal energy generated. For the thermal conductivity and thermal resistivity measurements was used glycerine as a standard. At $25{ }^{\circ} \mathrm{C}$ the thermal conductivity of glycerol is equal to $0.185 \mathrm{~W} / \mathrm{mK}$, being this value in according to the literature. The effect of the addition of $\mathrm{C} / \mathrm{Zn}$ nanoparticles in the fuel was observed by thermal conductivity and thermal resistivity. Tables 2 to 5 list values of thermal conductivity and thermal resistivity.

Table 2: Thermal conductivity and thermal resistivity of fuels with $60 \mathrm{ppm}$ of C / Zn.

\begin{tabular}{ccc}
\hline Sample, 60ppm & $\begin{array}{c}\text { Thermal conductivity } \\
(\mathbf{W} / \mathbf{m K})\end{array}$ & $\begin{array}{c}\text { Thermal resistivity } \\
\left({ }^{\mathbf{O}} \mathbf{C . c m} / \mathbf{w}\right)\end{array}$ \\
\hline Alcohol & 0.188 & 531.2 \\
Diesel & 0.126 & 796.2 \\
Biodiesel & 0.151 & 663.6 \\
\hline
\end{tabular}

Table 3: Thermal conductivity and thermal resistivity of fuels with $120 \mathrm{ppm}$ of C / Zn.

\begin{tabular}{ccc}
\hline $\begin{array}{c}\text { Sample, } \\
\text { 120ppm }\end{array}$ & $\begin{array}{c}\text { Thermal conductivity } \\
\text { (W/mK) }\end{array}$ & $\begin{array}{c}\text { Thermal resistivity } \\
\left({ }^{\circ} \mathbf{C} \cdot \mathbf{c m} / \mathbf{w}\right)\end{array}$ \\
\hline Alcohol & 0.191 & 523.4 \\
Diesel & 0.125 & 800.1 \\
Biodiesel & 0.149 & 671.3 \\
\hline
\end{tabular}

Table 4: Thermal conductivity and thermal resistivity of fuels with $240 \mathrm{ppm}$ of C / Zn.

\begin{tabular}{ccc}
\hline $\begin{array}{c}\text { Sample, } \\
\text { 240ppm }\end{array}$ & $\begin{array}{c}\text { Thermal conductivity } \\
(\mathbf{W} / \mathbf{m K})\end{array}$ & $\begin{array}{c}\text { Thermal resistivity } \\
\left({ }^{\mathbf{C}} \mathbf{C . c m} / \mathbf{w}\right)\end{array}$ \\
\hline Alcohol & 0.199 & 502.1 \\
Diesel & 0.123 & 812.0 \\
Biodiesel & 0.148 & 675.4 \\
\hline
\end{tabular}


Table 5: Thermal conductivity and thermal resistivity of diesel/biodiesel blends with 60,120 and $240 \mathrm{ppm}$ of C / Zn.

\begin{tabular}{ccc}
\hline $\begin{array}{c}\text { Diesel / biodiesel } \\
\text { mixtures }\end{array}$ & $\begin{array}{c}\text { Thermal conductivity } \\
(\mathbf{W} / \mathbf{m K})\end{array}$ & $\begin{array}{c}\text { Thermal resistivity } \\
\left({ }^{\circ} \mathbf{C} . \mathbf{c m} / \mathbf{w}\right)\end{array}$ \\
\hline 60ppm & 0.138 & 719.7 \\
$120 \mathrm{ppm}$ & 0.145 & 689.5 \\
$240 \mathrm{ppm}$ & 0.148 & 677.3 \\
\hline
\end{tabular}

Fig. 3 shows the influence of the addition of $\mathrm{C} / \mathrm{Zn}$ nanoparticles as a function of concentration on the thermal conductivity of dispersions after 15 min of thermal stabilization.

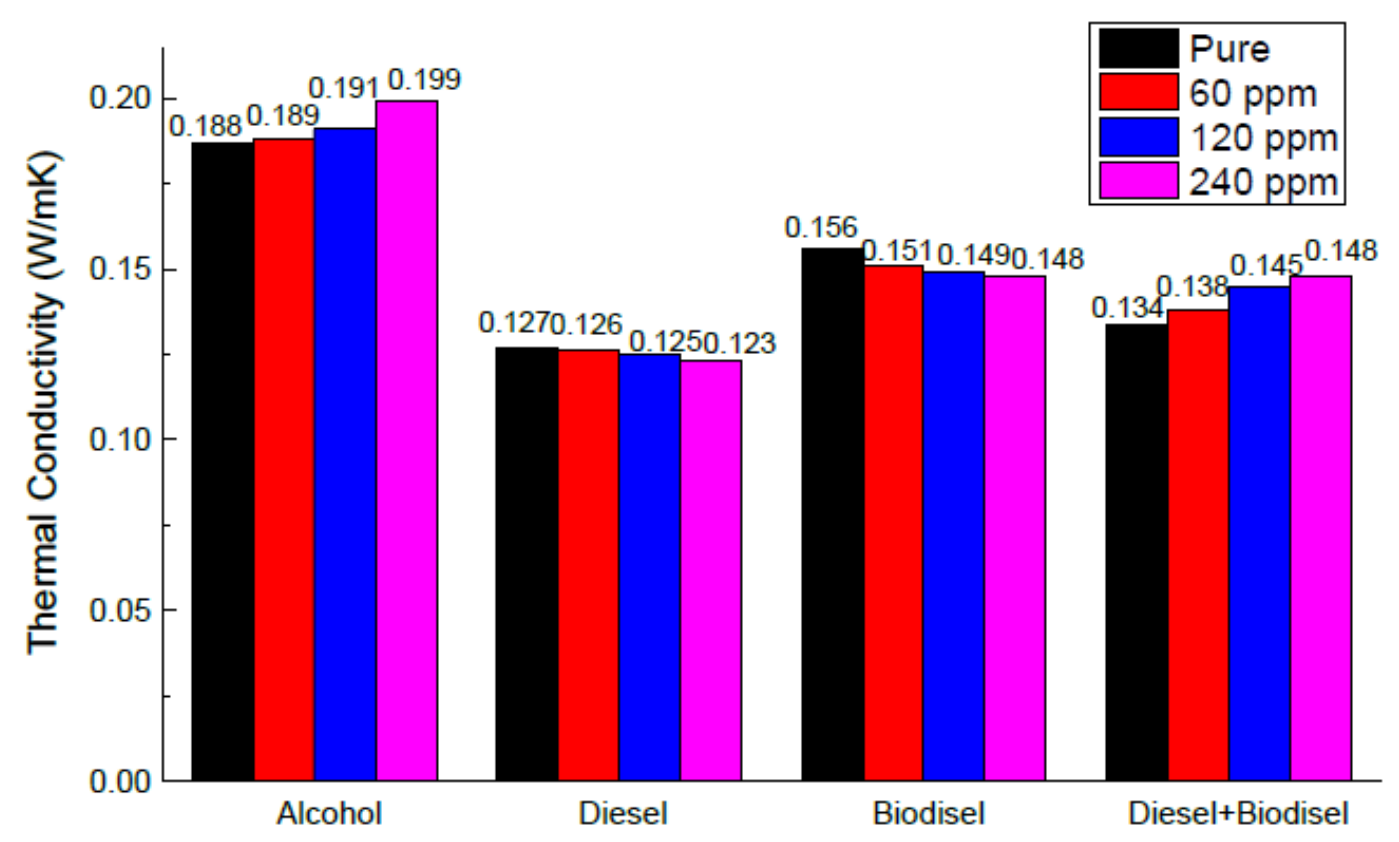

Fig. 3: Effect of $\mathrm{C} / \mathrm{Zn}$ on the thermal conductivity of fuels: alcohol, petro-diesel, biodiesel and diesel/biodiesel blend.

According to Fig. 3, the functional nanocomposite showed potential to act as an additive for improving the thermal conductivity of the alcohol fuel. The thermal conductivity of the fuel alcohol is equal to $0.187 \mathrm{~W} / \mathrm{mK}$ and with the addition of $\mathrm{C} / \mathrm{Zn}$ nanocomposite the conductivity showed an increase reaching $0.199 \mathrm{~W} / \mathrm{mK}$ at the concentration of $240 \mathrm{ppm}$ of $\mathrm{C} / \mathrm{Zn}$. The increase in thermal conductivity, generated by the addition of $\mathrm{C} / \mathrm{Zn}$ in fuel alcohol, is due to its polarity. $\mathrm{C} / \mathrm{Zn}$ nanoparticles interact more efficiently with polar molecules of solvent. The same phenomenon was not observed for the diesel and biodiesel that showed a decrease in thermal conductivity. In nonpolar liquids, such as diesel and biodiesel, the forces acting on them are weak forces known as Van der Waals forces, therefore they have little interaction with the $\mathrm{C} / \mathrm{Zn}$ nanoparticles. The mixture of diesel and biodiesel showed a different behavior, where the addition of $\mathrm{C} / \mathrm{Zn}$ particles contributed to an increase of the thermal conductivity of the mixture. The mixture of diesel and biodiesel formed a single phase system, displaying a better interaction with the $\mathrm{C} / \mathrm{Zn}$ particle, than with their individual components. Similarly, for the thermal resistivity, is characterized the difficulty of the material in conducting heat. 
In the case of nonpolar fuels such as diesel and biodiesel, which showed little interaction with the $\mathrm{C} / \mathrm{Zn}$ added, it is possible to observed that the increase in the number of dispersed particles, causes a decrease in thermal conductivity. In fuel alcohol, the addition of the nanoparticles favors an increase in thermal conductivity.

\section{Conclusion}

From of the modulation of the concentration of the C/Zn particles dispersed in the alcohol, the parameter thermal conductivity can be controlled. Since, $\mathrm{C} / \mathrm{Zn}$ additive leads to an increasing of the thermal conductivity of alcohol, while a decrease of the thermal conductivity as a function of the number of dispersed particles is identified for diesel and biodiesel, the polar character of the alcohol and its hydrogen bond exhibit influence on the additive-fuel interaction.

\section{Acknowledgements}

One of authors, B. S. Potensa is grateful to the scholarship CNPq/PIBIC, UNESP/FCT. M. A. L. Nobre is grateful to CNPq/Universal for financial support.

\section{References}

[1] Flávia C. C. Oliveira, et al.: Química Nova na Escola. Vol. 1 (2007), p. 3.

[2] M. A. L. Nobre, E. Longo, E. R. Leite, J. A. Varela: Mater. Lett. Vol.28 (1996), p. 215.

[3] P.W. Atkins, L. Jones: Princípios de química: questionando a vida moderna e o meio ambiente. 5.ed., Porto Alegre: Bookman, 2012, pp. 965.

[4] E. R. Leite, M. A. L. Nobre, M. Cegueira, E. Longo, J. A. Varela: J. Amer. Ceram. Soc. Vol. 80 (1997), p. 2649.

[5] J. Matos, P. S. Poon, S. Lanfredi, M. A. L. Nobre: Fuel, Vol. 107 (2013), p. 503.

[6] S. S. Borges, M. Korn: Química Nova. Vol. 25 (2002), p. 558.

[7] Application note, KD2 Pro, Decagon Devices.

[8] KD2 Pro Thermal Properties Analyzer, Operator's Manual, Version 12.

[9] P. G. P. Moraes, S. Lanfredi, J. Matos, M. A. L. Nobre: Photocatalytic Properties of a Hybrid Composite of $\mathrm{ZnO}$ with Amorphous Carbon Containing Homogeneous Dispersion of Zn Metallic. In: The Annual World Conference on Carbon, Rio de Janeiro, Vol. 1, 2013. 


\section{Brazilian Ceramic Conference 58}

10.4028/www.scientific.net/MSF.820

\section{New Additive Type Amorphous-Carbon/Zn Modifier of the Thermal Conductivity of Alcohol Fuel} 10.4028/www.scientific.net/MSF.820.384

\section{DOI References}

[2] M. A. L. Nobre, E. Longo, E. R. Leite, J. A. Varela: Mater. Lett. Vol. 28 (1996), p.215.

10.1016/0167-577X(96)00062-6

[4] E. R. Leite, M. A. L. Nobre, M. Cegueira, E. Longo, J. A. Varela: J. Amer. Ceram. Soc. Vol. 80 (1997), p.2649.

10.1111/j.1151-2916.1997.tb03167.x

[5] J. Matos, P. S. Poon, S. Lanfredi, M. A. L. Nobre: Fuel, Vol. 107 (2013), p.503.

10.1016/j.fuel.2012.11.007

[6] S. S. Borges, M. Korn: Química Nova. Vol. 25 (2002), p.558.

10.1590/S0100-40422002000400009 